\title{
Assessment of Constraints to the Adoption of Technologies Promoted by the Integrated Pest Management Training Program in Cotton-Based Cropping Systems in Western Burkina Faso
}

\author{
Souleymane Nacro' ${ }^{1}$, Karim Sama ${ }^{2}$ \\ ${ }^{1}$ Programme de GIPD s/c FAO, Ouagadougou, Burkina Faso \\ ${ }^{2}$ Université Polytechnique de Bobo-Dioulasso, Bobo Dioulasso, Burkina Faso \\ Email: snacro2006@yahoo.fr
}

How to cite this paper: Nacro, S. and Sama, K. (2018) Assessment of Constraints to the Adoption of Technologies Promoted by the Integrated Pest Management Training Program in Cotton-Based Cropping Systems in Western Burkina Faso. Advances in Entomology, 6, 148-159. https://doi.org/10.4236/ae.2018.62011

Received: March 30, 2018

Accepted: April 24, 2018

Published: April 27, 2018

Copyright $\odot 2018$ by authors and Scientific Research Publishing Inc. This work is licensed under the Creative Commons Attribution International License (CC BY 4.0).

http://creativecommons.org/licenses/by/4.0/

\section{(c) (i) Open Access}

\begin{abstract}
Our study was conducted from August 2008 to March 2009 in the Houet province, western Burkina Faso. It consisted in the assessment of the constraints to the adoption by cotton growers of technologies promoted by the IPM program through Farmers' Field Schools in cotton-cereals-livestock systems. We did so by surveying a sample of 185 farmers trained in IPM and by describing farmers' practices before and after the training in IPM. The results showed that the average dose of organic manure, NPK and urea used by famers after their training were respectively 3.8 tons $/ \mathrm{ha}, 163 \mathrm{~kg} / \mathrm{ha}$ and $65 \mathrm{~kg}$ /ha as compared with 2.4 tons/ha, $140 \mathrm{~kg} / \mathrm{ha}$ and $51 \mathrm{~kg} / \mathrm{ha}$ before the training. Regarding the use of pesticides, $94.6 \%$ of farmers used protection equipment during the sprayings after the training against $21.6 \%$ of them before the training. However, the average number of sprays did not vary significantly. It was 6 before the training and only 5 after. The botanical pesticides were used by $31 \%$ of farmers after the training as compared with $0 \%$ of users before the training in IPM. The training did not affect much crop yields. The constraints identified and classified according to their relative importance included the lack of agricultural equipment, and animals for ploughing, difficulties in inputs access, labor shortage, the lack of organic manure, and marketing problems. These technical, social and economic constraints have been analyzed and recommendations have been made to work them out.
\end{abstract}




\section{Keywords}

IPM, Cotton-Cereals-Livestock, Production Systems, Botanicals, Farmers'

Field Schools, Constraints

\section{Introduction}

Cotton is the second export product of Burkina Faso. With a production of 720,000 metric tons of seed cotton in 2006, Burkina Faso remains the top African producer. About 200,000 agricultural households make directly their living on cotton growing and almost 3,000,000 Burkinabé benefit indirectly from this sub-sector [1]. However, cotton is subject to many enemies in the field and the insect pests are responsible for a significant yield loss. Farmers use exclusively chemical pesticides to control these insect pests. Consequently, the amount of pesticides used is constantly increasing as the cotton production is expanding. For example, in Burkina Faso, the quantity of insecticides used to control cotton insect pests amounted 1,750,000 liters in 1998 [2]. This practice threatens agricultural ecosystems and human and animal health. The World Health Organization (WHO) estimates that 20,000 is the number of accidental deaths per year resulting from pesticide poisoning worldwide, most of them occurring in developing countries [3]. Thus, the use of sustainable control methods to manage pests is by far the best approach. The use of chemical pesticides should be envisaged as the last resort.

The effects of chemical pesticides on human health and environment, and the sustainability of the agricultural production systems must be carefully considered during the implementation of IPM. The objective of the IPM program is to reduce the reliance of farmers to agrochemicals by offering them sustainable alternatives. In Burkina Faso, the program includes rice, vegetables and cotton for which the use of pesticides remains a major concern [4]. The IPM program aims at strengthening the national agricultural extension system by training agricultural technicians and small scale farmers. Since 2005, the IPM program in collaboration with the National Union of Cotton Growers (NUCG-B) and other partners trains cotton growers in the intensification and the diversification of the cotton-based cropping systems, means cotton-cereals-livestock. This initiative was known as the promotion of Good Agricultural Practices (GAP). The training was delivered to cotton growers of Houet, one of the 45 provinces that form Burkina Faso and where the cotton-based cropping systems are the most dominant. During the training conducted in a participatory way called Farmers' Field Schools (FFS), farmers work under the supervision of an extension officer who is rather a facilitator than an instructor. Indeed, the field school is an extension system that values local expertise by getting farmers involved at all stages of the training from the diagnosis of the problem, to the identification and the implementation of the best solutions and the evaluation of the results. Through FFS, 
the IPM program disseminates appropriate and simple technologies that can help increase agricultural productivity. Three years after the start of the training of cotton growers in the Houet province, there was a need to assess the level of adoption of the technologies promoted by the program and to evaluate the main constraints to the implementation of these technologies.

Our study aims therefore at assessing the main constraints to the adoption of the agricultural technologies that were exposed to farmers during their training in the Houet province.

\section{Material and Methods}

\subsection{Study Area and Training Main Content}

This study was conducted in the cotton belt of Burkina Faso, in the Houet province whose capital city is Bobo-Dioulasso, western Burkina Faso. The geographical coordinates of the province are $11^{\circ} 33^{\prime}$ north latitude and $4^{\circ} 25^{\prime}$ west longitude.

Our study was conducted in Bama and Bobo-Dioulasso departments, 2 out of 13 departments of the province. Yearly average rainfalls vary from $800 \mathrm{~mm}$ to $1200 \mathrm{~mm}$. The coolest month of the year is December $\left(21^{\circ} \mathrm{C}\right)$ while the hottest month is October $\left(30^{\circ} \mathrm{C}\right)$. Average relative humidity varies from $50 \%$ in December to $80 \%$ in August.

All the trainings were conducted each year from June to November. The main content of each training was as follow:

- soil management and preparation;

- feed plants management;

- sowing and weeding;

- pests and diseases associated with crops and their management;

- insect pests and plant diseases scouting;

- analysis of agro-ecosystem;

- post-harvest technologies;

- economical analysis.

\subsection{Data Collection}

A tracking sheet of trained growers was prepared and used to collect data on the agricultural practices used by farmers before and after the training.

\subsection{Farmers' Survey}

A structured survey was conducted with a sample of 185 cotton growers organized into 12 groups. One group received the training in 2005-2006 while the 10 were trained in 2006-2007 and the remaining one received the training in 2007-2008. For each group, the survey was administered individually to every single farmer without using any interpreter. The survey allowed the assessment of the constraints to the adoption of the technologies promoted by the IPM Program. The problems were ranked from the most to the less important. 


\subsection{Yield Measurement}

Cotton and corn yields were estimated three consecutive years before (2003, 2004 and, 2005) and after the training (2006, 2007 and, 2008). Both farm area and yield were collected from each surveyed farmer.

\subsection{Data Analysis}

Data on agricultural inputs were analyzed using Microsoft EXCEL 2007. Prior to analysis, each constraint was assigned a score that reflected its importance. The Principal Component Analysis (PCA) and the Hierarchical Clustering were performed using XLSTAT 2010.

\section{Results}

\subsection{Fertilizer Management}

\subsubsection{Organic Fertilizer Management}

As many as $91.9 \%$ of the surveyed farmers used organic manure after the training against $57.3 \%$ before the training. The average dose of organic manure used on cotton and corn after training was 3.8 tons against an average of 2.4 tons/ha before the training (Table 1). Our results showed that for both cotton and corn, only $24.75 \%$ of farmers used organic manure from pits after the training as compared with $1.8 \%$ of them before the training.

\subsubsection{Mineral Fertilizers' Management}

The average dose of NPK used on cotton was $163 \mathrm{~kg} / \mathrm{ha}$ after the training against $140 \mathrm{~kg} / \mathrm{ha}$ before the training. For corn, the average dose was $162 \mathrm{~kg} / \mathrm{ha}$ after training as compared with $133 \mathrm{~kg} /$ ha before the training (Table 1 ).

The average dose of urea used on cotton was $65 \mathrm{~kg} / \mathrm{ha}$ after training against 51 $\mathrm{kg} / \mathrm{ha}$ before training (Table 1). On corn, the average dose of urea was $70 \mathrm{~kg} / \mathrm{ha}$ after training as compared with $52 \mathrm{~kg} /$ ha before training.

\subsubsection{Insecticides Management}

The doses of insecticides used on cotton were slightly the same before and after

Table 1. Summary of average doses of organic and mineral fertilizer used before and after the training.

\begin{tabular}{cccccc}
\hline \multirow{2}{*}{ Parameters } & \multicolumn{2}{c}{ After training } & \multicolumn{2}{c}{ Before training } \\
\cline { 2 - 6 } & Crop & Dose $(\mathrm{kg} / \mathrm{ha})$ & $\begin{array}{l}\text { Standard } \\
\text { deviation }\end{array}$ & Dose (kg/ha) & $\begin{array}{c}\text { Standard } \\
\text { deviation }\end{array}$ \\
\hline $\begin{array}{c}\text { Organic } \\
\text { manure }\end{array}$ & Cotton & 3781 & 1517 & 2397 & 1547 \\
NPK & Corn & 3751 & 1557 & 2430 & 1521 \\
& Cotton & 163 & 31 & 140 & 26 \\
Corn & 162 & 35 & 133 & 28 \\
& Cotton & 65 & 24 & 51 & 8 \\
\hline
\end{tabular}


training means an average of $1 \mathrm{l} / \mathrm{ha}$. The use of botanical pesticides was one of the new practices that were recommended by the IPM program. Our results showed that $31 \%$ of farmers used botanical insecticides after the training. These botanicals were mainly made of solutions obtained from neem leaves or seeds. The IPM program also recommends that farmers observe weekly their fields in order to make sound decisions. When this was done, the number of chemical sprayings dropped from 6 (before the training) to 5 (after the training) (Figure 1).

Furthermore, our investigation has allowed to prepare the list of the different types of insecticides used by cotton growers before and after the training. So, in addition to Endosulfan (350 g/l), Cypermethrin (36 g/l) and Profenofos, another active ingredient such as Acetamiprid was also used.

\subsubsection{Insecticide Use Safety}

The World Health Organization (WHO), reported that 20,000 is the number of accidental deaths per year resulting from pesticide poisoning worldwide and the majority of these deaths occurs in developing countries [3]. With this in mind, the IPM program recommends a safe use of pesticides before, during and after the spraying of pesticides.

Our results showed that regarding the specific issue of pesticide storage before use, $84.9 \%$ of trained farmers stocked them in a store before use whereas before training they were only $20.5 \%$ (Figure 2 ).

Before the training, $67 \%$ of farmers used to keep pesticides in their homes while after training, they were only $4.3 \%$ to do so. Regarding the use of protective equipment during the sprayings, our results showed that $94.6 \%$ of farmers were protected after receiving this training, whereas before the training they were only $21.6 \%$ (Figure 3 ). The containers were buried by $65.4 \%$ of the farmers after the training against $12.43 \%$ before the training. Before the training, $3.24 \%$ of farmers against $20 \%$ of them after the training burnt the containers (Figure 4). After the training, $11.35 \%$ of farmers threw away the containers in the nature against $81.08 \%$ before the training.

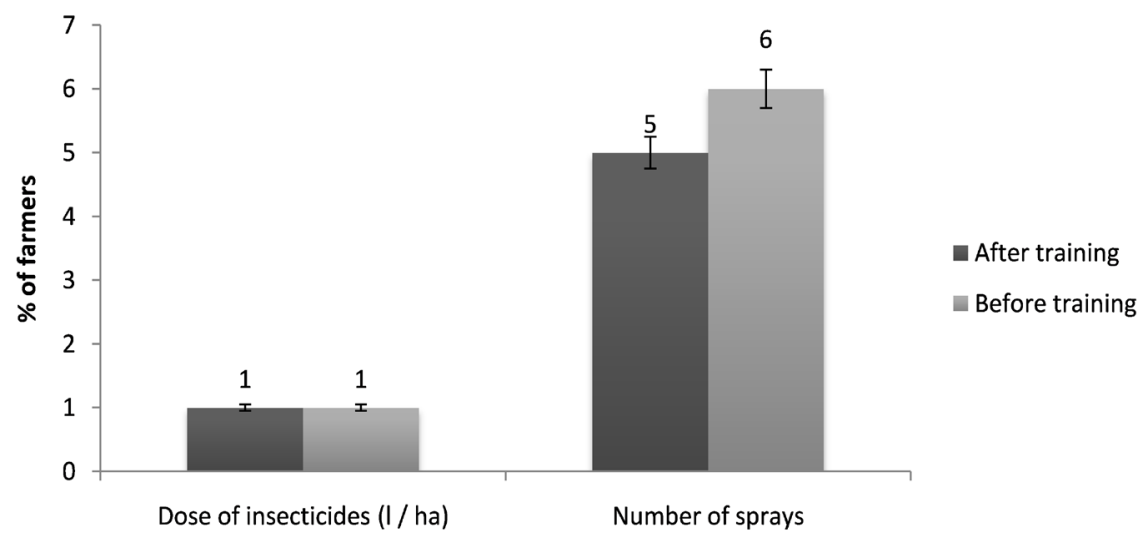

Figure 1. Management of chemical insecticides used by cotton farmers, Burkina Faso, 2009. 


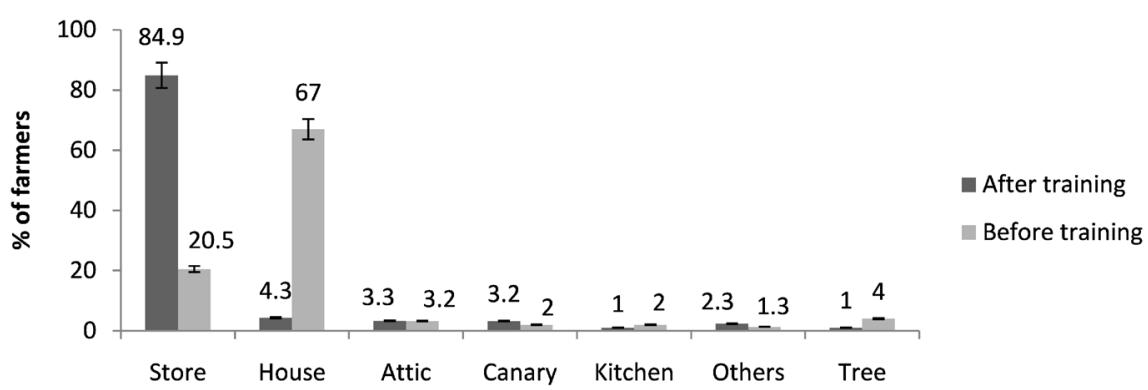

Figure 2. Distribution of farmers according to pesticide storage before use, Burkina Faso, 2009.

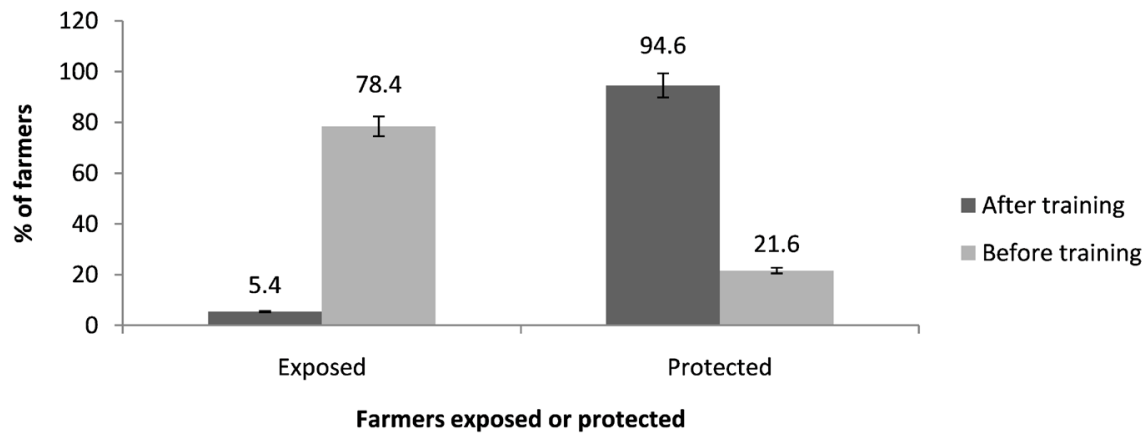

Figure 3. Distribution of famers based on the use of protective equipment, Burkina Faso, 2009.

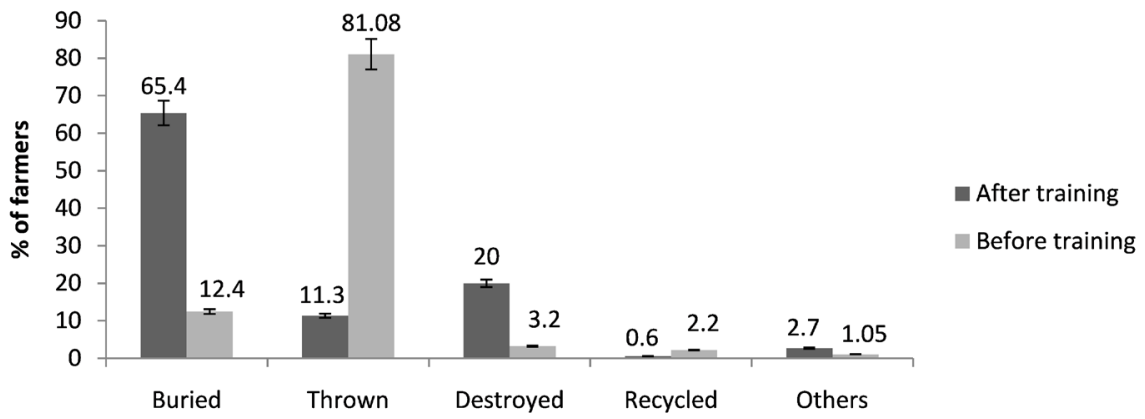

Figure 4. Distribution of farmers according to the destination of the packaging after the use of the products, Burkina Faso, 2009.

\subsubsection{Yields}

The cotton yields ranged from 0.84 to 1.5 tons/ha (average yield of 1.1 tons/ha) before the training whereas they varied from 0.7 to 1.2 tons/ha after the training (average yield of 1 ton/ha). The highest average yield of cotton was obtained by the group Sinignassigui (1.5 tons/ha) before the training against 1.2 tons/ha obtained by the groups Sagnon, Yegueresso I and Yeguewisso biéna after the training. Regarding the average yields of corn, they were 2.07 tons/ha before the training against 1.6 tons/ha after the training. The group Fintalabo has obtained the average highest yield before the training means 2.5 tons/ha whereas after the training, it was obtained by the groups Gnongontalon and Zizène means 2 tons/ha (Table 2). 
Table 2. Summary of average yields reported by different groups before and after the training.

\begin{tabular}{|c|c|c|c|}
\hline \multirow{2}{*}{ Groups } & \multirow{2}{*}{ Crops } & \multicolumn{2}{|c|}{ Average yields } \\
\hline & & Before training & After training \\
\hline \multirow{2}{*}{ Badegna Alladary } & Cotton & 0.99 & 0.80 \\
\hline & Corn & 2.24 & 1.30 \\
\hline \multirow{2}{*}{ Fintalabo } & Cotton & 0.98 & 0.90 \\
\hline & Corn & 2.50 & 1.70 \\
\hline \multirow{2}{*}{ Gnongontalon } & Cotton & 0.90 & 0.80 \\
\hline & Corn & 2.10 & 2.00 \\
\hline \multirow{2}{*}{ Gwendegesso } & Cotton & 1.05 & 1.00 \\
\hline & Corn & 2.35 & 0.90 \\
\hline \multirow{2}{*}{ Kuini } & Cotton & 1.34 & 0.90 \\
\hline & Corn & 1.61 & 1.40 \\
\hline \multirow{2}{*}{ Sababougnouma } & Cotton & 0.84 & 1.00 \\
\hline & Corn & 2.10 & 1.70 \\
\hline \multirow{2}{*}{ Sagnon } & Cotton & 1.32 & 1.20 \\
\hline & Corn & 1.96 & 2.00 \\
\hline \multirow{2}{*}{ Sinignassigui } & Cotton & 0.99 & 1.00 \\
\hline & Corn & 1.45 & 1.95 \\
\hline \multirow{2}{*}{ Tindbeogo } & Cotton & 1.50 & 1.10 \\
\hline & Corn & 1.95 & 1.60 \\
\hline \multirow{2}{*}{ Yegueresso I } & Cotton & 1.35 & 1.20 \\
\hline & Corn & 2.01 & 1.40 \\
\hline \multirow{2}{*}{ Yeguewisso Biéna } & Cotton & 1.20 & 1.20 \\
\hline & Corn & 2.32 & 1.44 \\
\hline \multirow{2}{*}{ Zizene } & Cotton & 1.24 & 1.10 \\
\hline & Corn & 2.30 & 2.00 \\
\hline
\end{tabular}

\subsubsection{Constraints Assessment}

We identified eight main constraints to the adoption of the technologies promoted by the IPM Program. Figure 5 shows the proportion of farmers for each main constraint. The top constraint was the insufficiency of agricultural equipment (for ploughing, fertilizer application, organic manure and harvest transportation in the fields and at home, pits digging and pesticides sprayings). This constraint appeared with a frequency of $29.4 \%$.

The proportion of farmers who did not have draft animals and who could not access agricultural inputs was respectively $13.2 \%$ and $10 \%$. Climatic constraints like drought were reported by $8.4 \%$ of the farmers. The proportion of farmers associated with the lack of labor and organic manure was respectively $6.4 \%$ and 


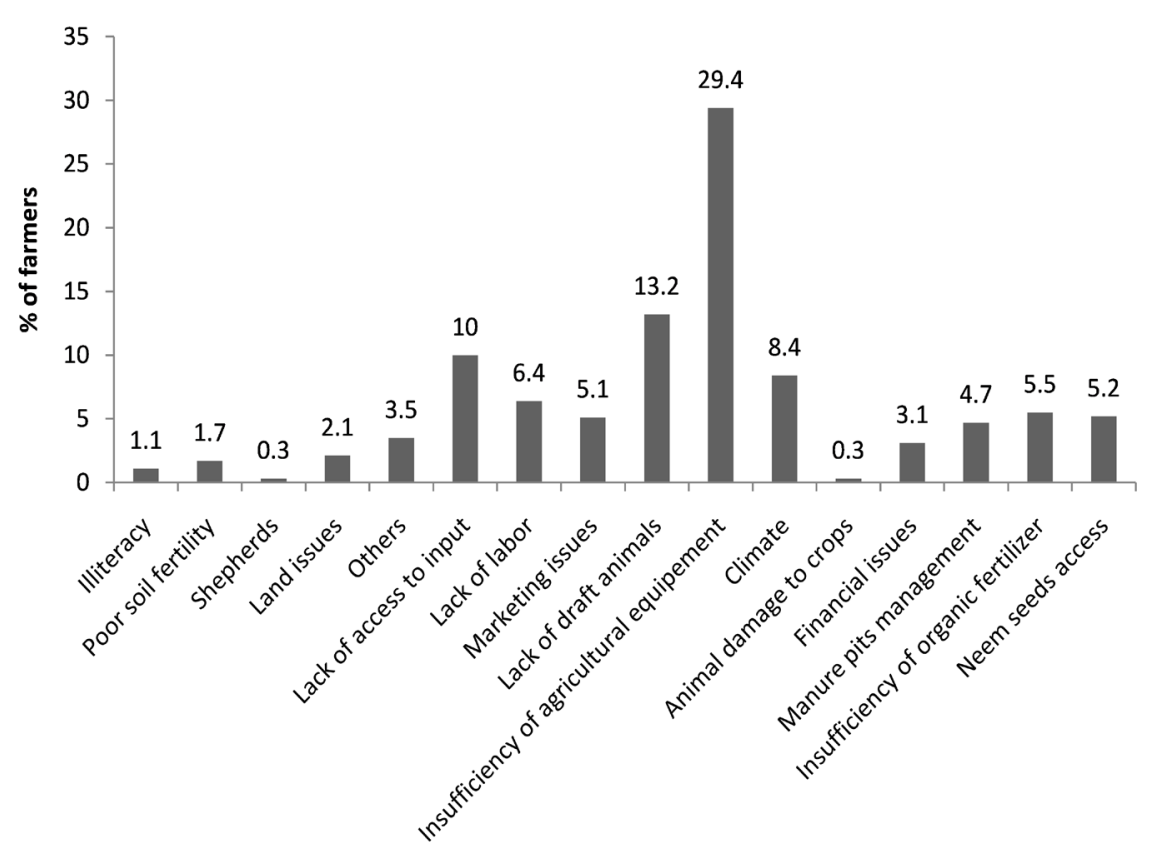

Figure 5. Proportion of farmers associated with the constraints to the adoption of technologies promoted by the IPM program, Burkina Faso, 2009.

5.5\%. Marketing and the problem of neem seeds availability for botanical pesticides were also mentioned as constraints by $5.2 \%$ and $5.1 \%$ respectively. The remaining constraints were mentioned by less than $5 \%$ of the farmers.

Numbers were assigned to the constraints randomly (Figure 6). The insufficiency of agricultural equipment (C1), the lack of labor (C4), land constraints (C7), illiteracy (C8) and the lack of draft animals (C9) appear to be related according to Figure 6. Inputs access constraint (C2), the lack of organic fertilizer (C3) and products marketing issue (C5) could form another class; the same thing could be applied to climatic constraints (C6) and the problem of neem seeds supply (C10). An ascending hierarchical classification was done and has allowed the drawing of a dendrogram (Figure 7).

According to the dendrogram (Figure 7), three classes of constraints have been identified: class 1, class 2 and class 3 . Class 1 included $45 \%$ of the farmers, $47 \%$ of them were in class 2 and $8 \%$ in class 3 . The majority of farmers surveyed were in class 2 .

Figure 8 presents the distribution of the constraints and the farmers on the axes F1 and F2. This confirms the results of Figure 6 and Figure 7 by highlighting the close relationship between farmers and the constraints (variables). Indeed, constraints C2, C3 and C5 were in the class 3 where the lowest proportion of farmers was recorded. Constraints $\mathrm{C} 6$ and $\mathrm{C} 10$, were associated with farmers of class 1 . Five constraints including $\mathrm{C} 1, \mathrm{C} 4, \mathrm{C} 7, \mathrm{C} 8$ and $\mathrm{C} 9$ were found in class 2 with $47 \%$ of farmers.

In overall, the majority of the identified constraints were associated with the highest proportion of surveyed farmers. 


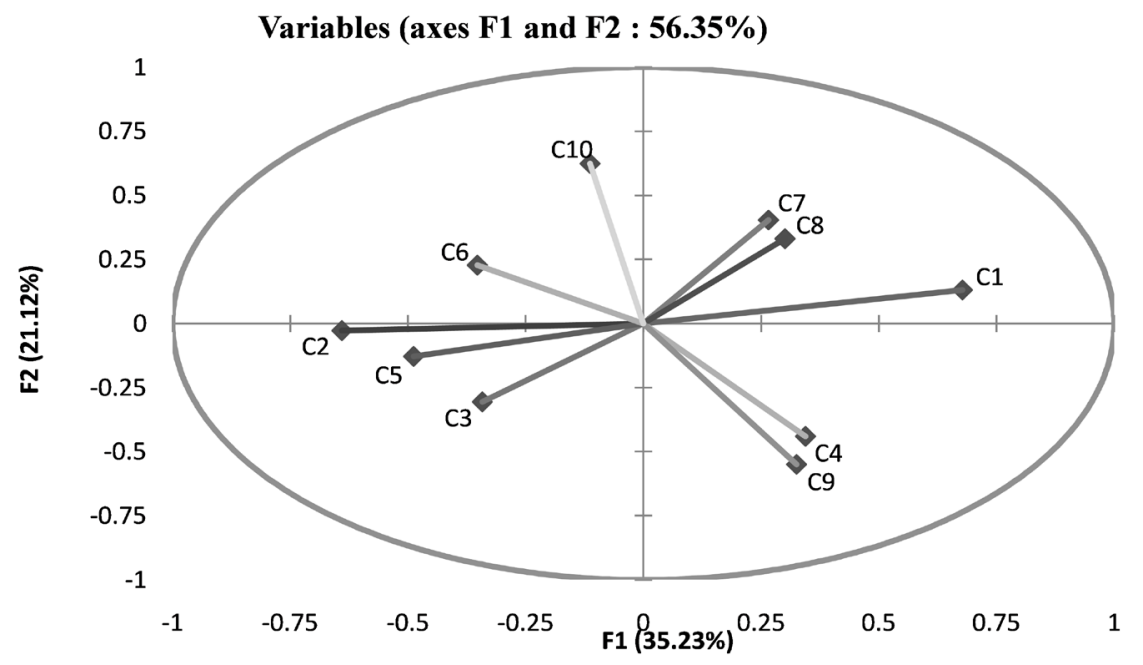

Figure 6. Constraints grouped into classes by Hierarchical Ascending Classification, Burkina Faso, 2009.

Dendrogramm

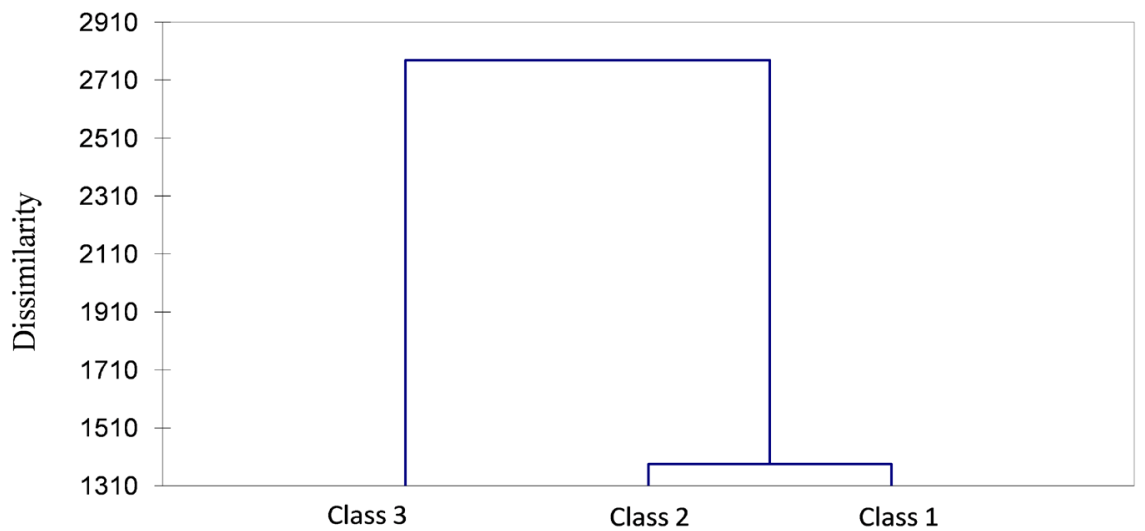

Figure 7. Dendrogram of the distribution of the constraints on the F1 and F2 axes by the Principal Component Analysis, Burkina Faso, 2009.

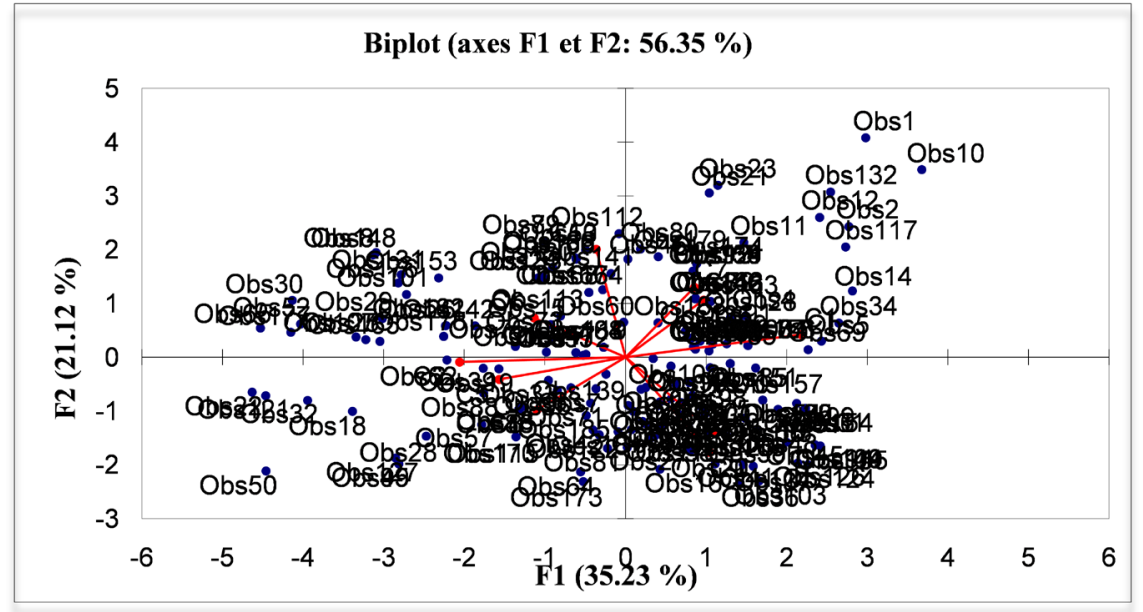

Figure 8. Farmers constraints spread over F1 and F2 axes by the Principal Component Analysis, Burkina Faso, 2009. 


\section{Discussion}

The improvement of farming in general depends on several agricultural practices that the IPM program has promoted. Soil fertility was assessed by [5] through the description of the main chemical characteristics in western Burkina Faso that includes the Houet province. This study reported that the majority of soils in this region had low organic matter levels with values ranging from less than $1 \%$ to $1.5 \%$. The causes of such poor soils in the region could be due to the abandonment of soil fallowing in the region due to land pressure, the absence or low use of organic manure and the low level of crop residues left in the fields after harvest. For these reasons, the IPM program has made the use of organic manure a prerequisite for the improvement of the agricultural productivity in the cotton belt of Burkina Faso. This message, according to our results has been heard by approximately $91.9 \%$ of the farmers after they have participated in the season-long training. Before the training, only $57.3 \%$ of the farmers used organic manure. However, even with this improvement, the average dose used by trained farmers, 3.8 tons/ha still remains below the recommended dose of 5 tons/ha. This result raises the issue of organic manure production. Composting of crop residues could be a solution to this problem. However, composting seems technically difficult. Indeed, our results showed that for both cotton and corn, only $24.75 \%$ of farmers used organic manure from pits after the training as compared to $1.8 \%$ of farmers before the training. The implementation of these pits is difficult because of the insufficiency of proper equipment and the high labor demand for digging in addition to the problems of pit maintenance.

For cropping intensification purposes, the IPM program recommends a dose of $200 \mathrm{~kg}$ of NPK and $100 \mathrm{~kg}$ urea per ha in cotton-based cropping systems. Results indicated that for cotton, the average dose of NPK was $163 \mathrm{~kg} / \mathrm{ha}$ after training compared to $140 \mathrm{~kg} / \mathrm{ha}$ before training. Even if there is an increase in the use of NPK due to the training, there is still a gap between the recommended dose and the used dose. Cotton growers receive inputs (chemical fertilizers, pesticides and seeds) from the cotton company, Sofitex, as a loan at the respective doses of $150 \mathrm{~kg}$ of NPK per ha and $50 \mathrm{~kg}$ of urea per ha. They pay back the loan to the company after they have sold their cotton. To be able to go for an intensive use of chemical fertilizers, farmers would have to buy the gap in the market. Most of them cannot afford these costly fertilizers. Thus, our results showed that $59.4 \%$ of farmers applied NPK at doses ranging between 100 and $150 \mathrm{~kg} / \mathrm{ha}$ and $32.8 \%$ of them used this fertilizer at doses between 150 and $250 \mathrm{~kg} / \mathrm{ha}$. Regarding urea, the average dose used was higher among farmers after the training with an average of $65 \mathrm{~kg} / \mathrm{ha}$ against $51 \mathrm{~kg} / \mathrm{ha}$ before the training. However, the proportion of $28.7 \%$ of farmers who used urea at doses ranging between 100 and 150 $\mathrm{kg} / \mathrm{ha}$ is an evidence of the positive effect of the training in terms of efforts made by farmers to intensify the production despite the numerous difficulties encountered. The same general conclusions also apply to corn. In fact, the situation is even worse with this crop. With corn, the quantity of chemical fertilizer that 
farmers receive from the cotton company depends on the area that is under cultivation with cotton. In other terms, the larger the area dedicated to cotton, the more likely farmers will get a high quantity of chemical fertilizers as a loan.

The training did not affect significantly the quantity of insecticides used by farmers. But the average number of sprays dropped from 6 to 5. Indeed, the IPM program recommends that pesticide application be based on field monitoring. Botanical pesticides are promoted by the IPM program as an alternative to chemical pesticides. Thus, $31 \%$ of farmers used neem extractions to spray their cotton on small areas (less than $0.5 \mathrm{ha}$ ). This modest result could be explained by the fact that chemical insecticides are given to farmers as a loan and they will pay them back whether or not they use them. Neem seeds are not yet commercially available and definitely farmers are careful, because the pressure of pests associated with cotton is so high and unpredictable, that they will not take a big risk by using largely botanical pesticides. The training has also produced good effects on the safety use of chemical pesticides. However it is encouraging that the percentage of farmers that properly handled chemical pesticides significantly increased after the training. In fact, the IPM training has led to profound changes in cotton production in the Houet province.

The results showed that training in IPM had almost no effects on yields. However, according to [3], several developing countries experienced successfully IPM projects. This is the case of Zimbabwe where average yield of 1.5 tons/ha of grain cotton was reported in IPM plots as compared to 0.7 ton/ha in non-IMP plots. During our study, contrary to the three years before the training and also the years 2006 and 2008 after the training, the year 2007 has been characterized by floods and severe droughts pockets in Burkina Faso and particularly in the Houet province where we conducted our study. This situation has negatively affected yields during this year. Also, we estimated the average yield after the training by considering the years 2006, 2007 and 2008. This is why most of the groups have obtained low yields after training compared to yields before the training. Indeed, the adoption and success of the technologies promoted by the IPM program are limited by the many constraints that minimize the positive effects on yields after the training. Agricultural equipment was identified by farmers as the top (29.4\% of all constraints) constraint. Small-scale cotton farmers have very limited debt capacity and the pay back of the inputs represents $41 \%$ of their total incomes. Thus, only $10 \%$ of this is reinvested in equipment [6]. The consequences of this constraint plus those of minor constraints negatively affect the adoption of the technologies promoted by the IPM program.

\section{Conclusions and Recommendations}

This study clearly showed how the participatory training in IPM through the Farmers' Field Schools in cotton-based cropping systems has resulted in the adoption of good agricultural practices that will in the long term improve the overall management of their farms. Meanwhile, several constraints remain un- 
solved. For these constraints to be resolved, all stakeholders need to work together.

\section{Acknowledgements}

We thank Mrs. Marie Noëlle Koyara, FAO Representative in Burkina Faso for allowing the publication of these results. This study was funded by the All ACP cotton intensification and diversification cropping systems project. We thank Dr. Caterina Batello from FAO, Rome for providing the necessary funds for this work. The first draft of this manuscript was reviewed by Dr. E.A. Heinrichs. We also thank Célestin Kaboré and Bernard Oula Ouattara for their assistance in the gathering of the data.

\section{References}

[1] Hauchard, V. (2005) Cotton Cropping and Soils Degradation in the Mouhoun Region of Burkina Faso. Ph.D. Thesis, Reims University, Champagne Ardennes, France, $428 \mathrm{p}$.

[2] Sanou, M. (2008) Effects of Extracts and Oil of Different Local Ecotypes of Azadirachta indica A. Juss (Meliaceae) in the Management of Insect Pests of Cotton at Farakô-Ba (Burkina Faso). M.Sc. Thesis, Abdou Moumouni University, Niamey, Niger, 60 p.

[3] Gnamou, A. (2004) Evaluation of the Constraints Associated with the Adoption of the Technologies Released by the National Integrated Plant Production and Pest Management of Rice in the Kou Valley: Proposition of Solutions. M.Sc. Thesis, Polytechnic University of Bobo-Dioulasso, Bobo-Dioulasso, 79 p.

[4] FAO (2006) Sub-Regional Participatory Training in Integrated Pest Management through Farmers' Field Schools for Benin. FAO, Burkina Faso and Mali. 54 p.

[5] Dakouo, D. (1991) The Maintain of Soil Fertility in the Cropping Systems with Intermediate Motorization. Case of the Cotton Belt of Western Burkina Faso. INERA/Cotton Research Program Cotton-ESFIMA, Bobo-Dioulasso, Burkina Faso, $49 \mathrm{p}$.

[6] FAO (2004) Sustainable Agrarian Systems, Vulnerability, and Good Agricultural Practices in Western Burkina Faso. Report of the FAO-INERA Workshop on Good Agricultural Practices, Bobo-Dioulasso, Burkina Faso, 166 p. 